\title{
The Effect of Chitosan Hydrolysate on Solanum Lycopersicum Plant Growth
}

\author{
Tatiana Timofeeva*, Daria Shtan'ko, Balzhima Shagdarova, Anton Zakurin, \\ Anastasiya Kamionskaya, and Alla II'ina \\ The Federal Research Centre "Fundamentals of Biotechnology" of the Russian Academy of \\ Sciences, Russia

\section{ORCID}

Tatiana Timofeeva; 0000-0001-6458-7371

Corresponding Author: Tatiana

Timofeeva; email:

timofeyka2033@mail.ru

Dates

Published 13 January 2022

Publishing services provided by

Knowledge E

(c) Tatiana Timofeeva et al. This article is distributed under the

terms of the

Attribution License, which

permits unrestricted use and

redistribution provided that the

original author and source are credited.

Selection and Peer-review under the responsibility of the 8 th Scientific and Practical Conference Conference Committee.

\section{G OPEN ACCESS}

Abstract. Chitosan is a well-known subjectof researchbecause of its beneficial properties, including its antibacterial and fungicidal activity, as well as its effect on plant physiology. One of the maindifficulties in agricultural chitosan implementation is the poor solubility of high molecular chitosan in water. Reducing themolecular weight of chitosan by acid hydrolysis increases its solubility. This research studied the effect of chitosan hydrolysate on the germination and development of Solanum lycopersicum L. plants. Theeffects of chitosan hydrolysate on seed germination, shoot development in the first week of development and in the first month of development were evaluated. According to the results, high concentrations of chitosan hydrolysate completely inhibited seed germination. However, short-term treatment by high concentrations of chitosan hydrolysate stimulatedthe development of seedlings, leading to substantially longerroots. Regular root application of high concentrations of chitosan hydrolysate inhibited plant development.

Keywords: chitosan hydrolysate, chitosan, plant growth regulators, plant germination

\section{Introduction}

Currently, agriculture sector faces major challenges due to the global uncontrolled use of pesticides and other agrochemicals. Despite significant progress in crop productivity, this can have a negative impact on the environment. The regular use of agrochemicals causes many adverse effects, including negative effects on non-target organisms, and soil degradation.

To overcome such challenges, new approaches to agriculture are being sought. Ways to reduce the use of synthetic compounds and introduce biodegradable agrochemicals based on biomaterials for efficient and safe use in agriculture are being explored.Chitosan is a promising compound which may have prospects for application in environmentally friendly agriculturesystems. Chitosan is a non-toxic, biocompatible and biodegradable biopolymer derived from chitin. Chitosan have a wide range of biological properties, such as antibacterial and antimycotic activities, film-forming ability $[1,2]$. 
Due to the prospects of its use in agriculturesector, the physiological effects of chitosan are being actively studied. Chitosan causes serious physiological changes in plants, affects the growth and differentiation of plant tissues, seed germination, enhances the rate of photosynthesis, acts as a causative agent of the synthesis of secondary plant metabolites [3].

A large number of studies describe chitosan as a polymer that promotes plant growth and development, affecting on germination [4], root elongation [5], seedling elongation, and increasing root activity [6].

The main reason which hinders the widespread use of chitin biopolymers, including chitosan, is their poor solubility at neutral $\mathrm{pH}$. A wide range of chitosan derivatives helps to solve the problem of their solubility in water or weakly acidic aqueous solutions $[7,8]$.

Another way to avoid this problem is the use productsofchitosan depolymerization. A decrease in the molecular weight of chitosan promotes its better solubility in water, increases its bioavailability, which affects its biological properties [9]. Earlier, it was shown the fungicidal activity of chitosan hydrolysate [10]. The aim of this study is to study the effect of chitosan hydrolysate on plant development.

\section{Materials and methods}

\subsection{Chitosanhydrolysate}

Chitosanhydrolysate $(\mathrm{CH})$, average molecular weight $33 \mathrm{kDa}(\mathrm{Ip}=2.1)$, at a concentration $10 \mathrm{mg} / \mathrm{ml}$, was obtained by hydrolysis of high molecular weight chitosan using nitric acid. The $\mathrm{pH}$ was adjusted at 5.5 with $\mathrm{NH}_{4} \mathrm{OH}$ solution [10].

The effect of chitosan hydrolysate was compared with a solution (control solution CS) of $\mathrm{HNO}_{3}$ and $\mathrm{NH}_{4} \mathrm{OH}$ respectively. Distilled water was used as a negative control.

\subsection{Plants}

Tomato seeds (Solanum lycopersicum L.) varieties Cherry Rosovy and Viking were used in experiments. The seeds were germinated in Petri dishes on moistened filter paper. The seeds were sterilized by incubation in $70 \%$ ethanol (1 min.), $10 \%$ sodium hypochlorite solution ( $3 \mathrm{~min}$.) then washed three times with sterile distilled water. 
TABLE 1: Experimental variants of the experiment to study the effect of chitosan hydrolysate on the development of shoots in the first week of growth.

\begin{tabular}{|c|c|c|c|c|c|c|}
\hline $\begin{array}{l}\text { Active } \\
\text { substance (initial } \\
\text { concentration) }\end{array}$ & \multirow{2}{*}{$\begin{array}{l}\text { Seed soaking } \\
\text { duration } \\
\text { constantly }\end{array}$} & \multicolumn{5}{|c|}{ Concentration (pH 5,5)[dilution] } \\
\hline $\begin{array}{lr}\text { CS: } & \mathrm{NH}_{4} \mathrm{OH} \\
(14 \mathrm{mM}) & +\end{array}$ & & {$[1 / 2]$} & {$[1 / 5]$} & {$[1 / 50]$} & {$[1 / 500]$} & {$[1 / 5000]$} \\
\hline & 22 hours & [1/2] & {$[1 / 5]$} & {$[1 / 5]$} & {$[1 / 50]$} & [1/500] \\
\hline \multirow{2}{*}{$\begin{array}{l}\mathrm{CH}(10 \mathrm{mg} / \mathrm{ml}) \text {, } \\
\text { containing } 14 \mathrm{mM} \\
\mathrm{NH}_{4} \mathrm{OH} \square 200 \mathrm{mM} \\
\mathrm{HNO}_{3}\end{array}$} & constantly & $\begin{array}{l}5 \\
{[1 / 2]}\end{array}$ & $\begin{array}{l}2 \mathrm{mg} / \mathrm{ml} \\
{[1 / 5]}\end{array}$ & $\begin{array}{l}0,2 \mathrm{mg} / \mathrm{ml} \\
{[1 / 50]}\end{array}$ & $\begin{array}{l}0,02 \mathrm{mg} / \mathrm{ml} \\
{[1 / 500]}\end{array}$ & $\begin{array}{l}0,002 \mathrm{mg} / \mathrm{ml} \\
{[1 / 5000]}\end{array}$ \\
\hline & 22 hours & $\begin{array}{l}5 \mathrm{mg} / \mathrm{ml} \\
{[1 / 2]}\end{array}$ & $\begin{array}{l}2 \mathrm{mg} / \mathrm{ml} \\
{[1 / 5]}\end{array}$ & $\begin{array}{l}0,2 \mathrm{mg} / \mathrm{ml} \\
{[1 / 50]}\end{array}$ & $\begin{array}{l}0,02 \mathrm{mg} / \mathrm{ml} \\
{[1 / 500]}\end{array}$ & $\begin{array}{l}0,002 \mathrm{mg} / \mathrm{ml} \\
{[1 / 5000]}\end{array}$ \\
\hline $\mathrm{H}_{2} \mathrm{O}$ (control) & constantly & - & - & - & - & - \\
\hline
\end{tabular}

\subsection{Study of chitosan hydrolysateeffecton seed germination and seedlingdevelopment in the first week of growth}

The effect of various concentrations $\mathrm{CH}$ and $\mathrm{CS}$ (Table 1) was checked by short-term soaking (a) and constant incubation in a solution (b).

a) Tomato seeds were soaked in $15 \mathrm{ml}$ plastic vials for 22 hours in $2 \mathrm{ml} \mathrm{CH}$ and CS of various concentrations. 50 seeds were used in each test. After 22 hours, 10 seeds were transferred to Petri dishes on filter paper soaked with $2 \mathrm{ml}$ of distilled water.

b) Tomato seeds were placed on Petri dishes (10 seeds in 1 Petri dish) on filter paper soaked with $2 \mathrm{ml}$ of $\mathrm{CH}$ and $\mathrm{CS}$ in appropriate dilutions.50 seeds were used in each test.

Germination conditions: $20-24{ }^{\circ} \mathrm{C}, 16$-hour photoperiod.

Germination energy was measured on the 4th day from the beginning of the experiment. The results were recorded on the 8th day. Seedling length and root length ware measured.

\subsection{Study of the tomato plants responseon regular root $\mathrm{CH}$ irriga- tion in the first month of growth}

Cherry tomato seeds were germinated for 4 days then the seedlings were replanted into $250 \mathrm{~cm}^{3}$ individual containers filled with soil. Starting from the 7th day from the moment of germination, the plants were irrigated three times a week with $\mathrm{CH}$ solution (at concentrations of $2 \mathrm{mg} / \mathrm{ml}, 0.2 \mathrm{mg} / \mathrm{ml}, 0.02 \mathrm{mg} / \mathrm{ml}$ ), CS (in appropriate dilutions) and distilled water as a control. Each variant was tested in 4 replicates. On the 25 th day, the 


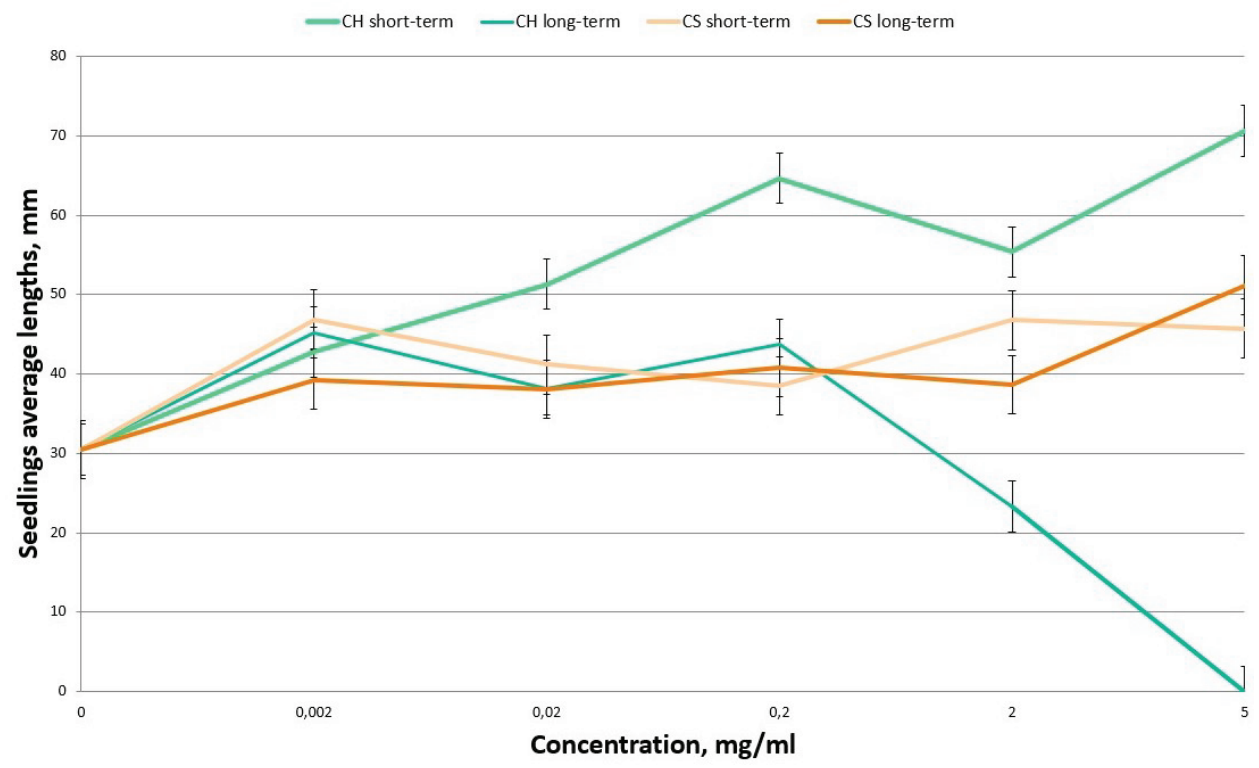

Figure 1: Comparison of the Cherry tomato seedlings average lengths on the 8th day of germination depending on solutions concentration. Light green line - short-term soaked $\mathrm{CH}$, dark green line - constant incubation with $\mathrm{CH}$, orange and yellow - CS constant incubation and short-term soaked respectively. Author's own work.

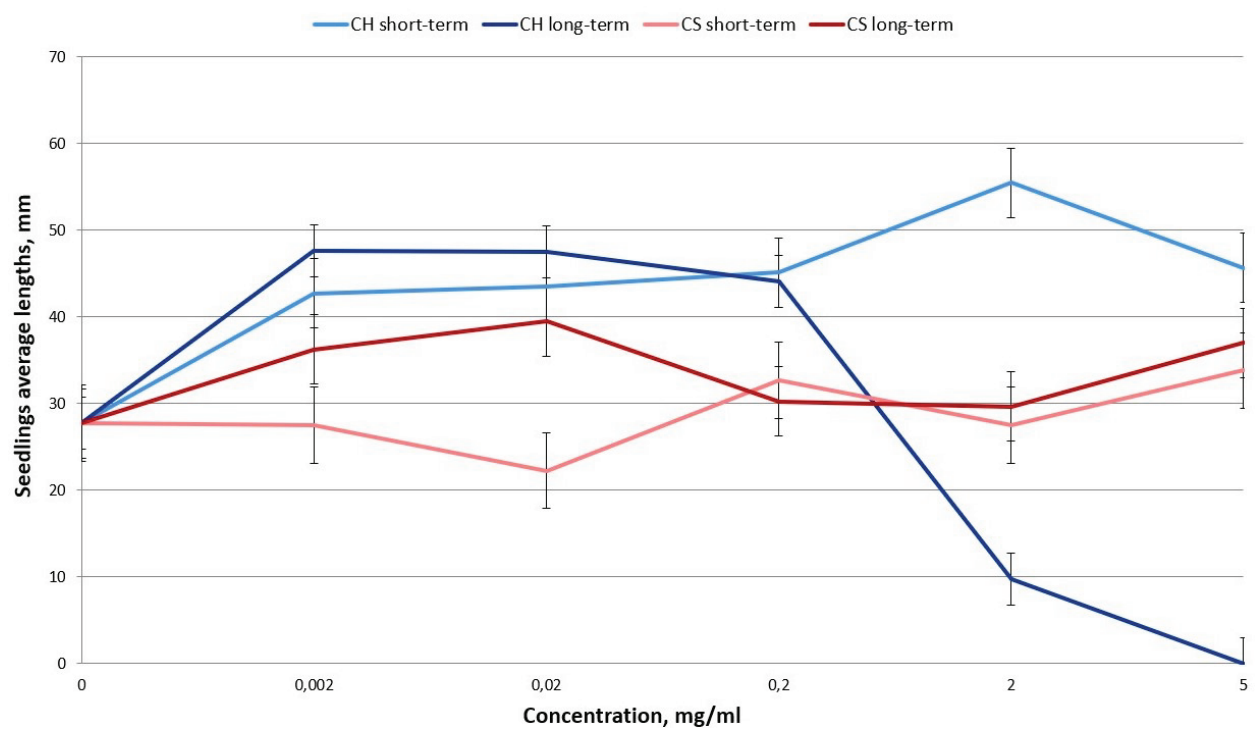

Figure 2: Comparison of the Viking tomato seedlings average lengths on the 8th day of germination depending on solutions concentration. Light blue - short-term soaked $\mathrm{CH}$, blue line - constant incubation with $\mathrm{CH}$, red and pink - CS constant incubation and short-term soaked respectively. Author's own work.

plants were removed from soil, roots were washed with running water. The maximum plant length, maximum root length, plant weight, root weight, and number of true leaves were measuredper plant. 


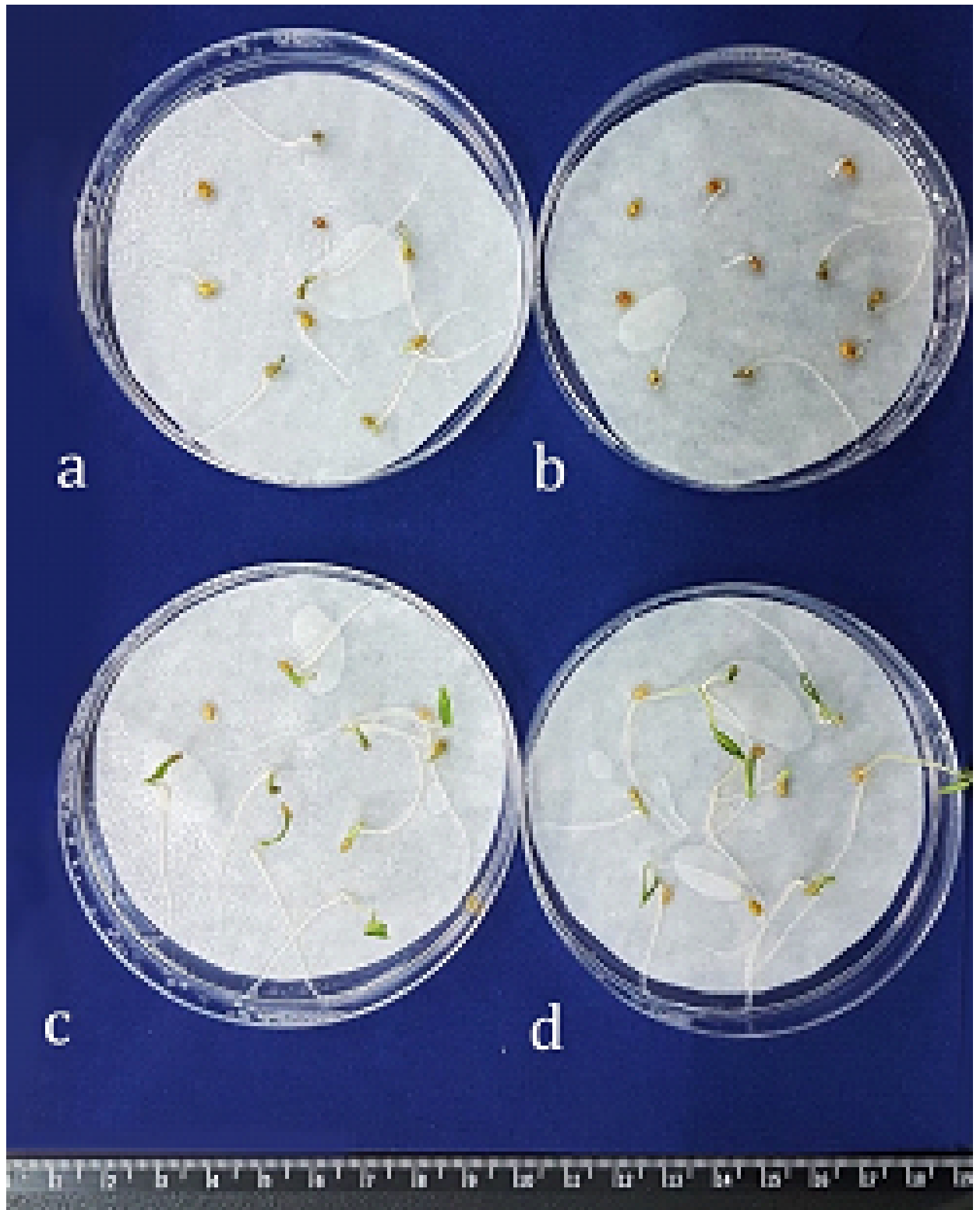

Figure 3: Short-term soaked variants $\mathrm{CH} 5 \mathrm{mg} / \mathrm{ml}(\mathrm{c}, \mathrm{d})$ compared with the control (a,b).

\section{Results and discussion}

Chitosan hydrolysate concentration $5 \mathrm{mg} / \mathrm{ml}$ completely inhibited seed germination. Lower concentrations of chitosan hydrolysate did not affect the germination energy. In all other variants, the germination energy index did not statistically differ from the control.

Short-term soaking Cherry tomato seeds for 22 hours in a $\mathrm{CH}$ solution with a concentration $5 \mathrm{mg} / \mathrm{ml}$, followed by transferring the seeds to distilled water showed the greatest average length of seedlings (Figure 1). Soaking tomato seeds in chitosan hydrolysatewith a concentration $5 \mathrm{mg} / \mathrm{ml}, 0.2 \mathrm{mg} / \mathrm{ml}$ and the subsequent transfer of seeds to distilled 

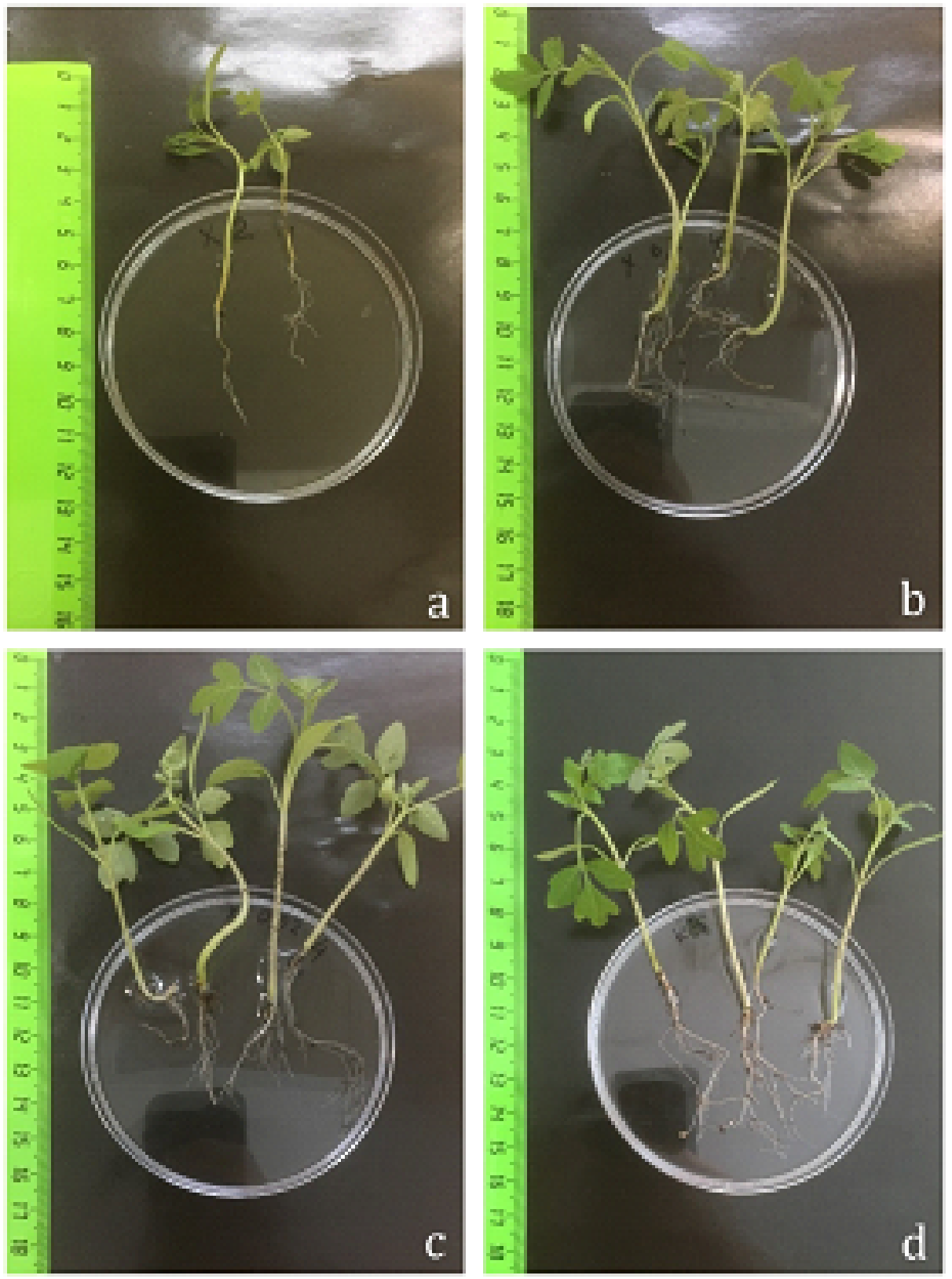

Figure 4: Cherry tomatoplantsirrigated with a) $2 \mathrm{mg} / \mathrm{mlCH}$; b) $0.2 \mathrm{mg} / \mathrm{mlCH}$; c) $0.02 \mathrm{mg} / \mathrm{mlCH}$, and d)distilled water as control -.

water allowed, on average, to increase the length of the roots by more than two times (respectively $231 \%, 201 \%$ ) compared to the control. The length of hypocotyls and roots pre-soakedsamples in chitosan hydrolysate with concentrations $5 \mathrm{mg} / \mathrm{ml}, 2 \mathrm{mg} / \mathrm{ml}$, and $0.2 \mathrm{mg} / \mathrm{ml}$ and transfer to distilled water was significantly higher than the length in all controls.

The statistical analysis of experimental datafor the Viking tomato variety showed similar results to Cherry tomato (Figure 2). The average length of seedling roots when 
soaked for 22 hours is also significantly longer than the control. Chitosan hydrolysate at a concentration of $5 \mathrm{mg} / \mathrm{ml}$ completely inhibited seed germination under constant exposure, and the transfer of seeds to distilled water in a case of short-term soakingterms results an increase in root length by $178 \%$ (Figure3).

As a result of both experiments the effect of a CS (which contained nitric acid and $\mathrm{NH}_{4} \mathrm{OH}$ ) were observed but the maximum increase in root length were observed at $\mathrm{CH}$ with the same content of nitric acid and $\mathrm{NH}_{4} \mathrm{OH}$.

Regular root irrigation of a $\mathrm{CH}$ solution with a concentration $2 \mathrm{mg} / \mathrm{ml}$ significantly inhibited growth of the root system and led to inhibition of plant growth in general. The inhibitory effect of a $\mathrm{CH}$ solution with a concentration $0.2 \mathrm{mg} / \mathrm{ml}$ was less significant (Figure 4). Lower concentration of chitosan hydrolysate, as well as control solutions, did not show statistically significant effect on plant development

Based on the obtained results, it can be concluded that chitosan hydrolysatehasanphysiologicalon plantgrowth. The constant presence of high concentrations of chitosan hydrolysate slows down plant development. At the same time, a short-term treatment has a stimulating effect. The differencebetweenlong-term and short-term exposure in chitosan hydrolysatepaves the way for further research. It is necessary to study in detail the effects of chitosan hydrolysate on plants at the physiological and molecularlevels.

\section{Acknowledgement}

This study was partially supported by Russian Foundation for Basic Research grant № 20-016-00205.

\section{References}

[1] Katiyar, Deepmala \& Hemantaranjan, A. \& Singh, Bharti. Chitosan as a promising natural compound to enhance potential physiological responses in plant: A review.Advances in Plants Agricultural Research. 2015;20(1). 1-9 doi.org/10.1007/s40502-015-0139-6.

[2] Zeng D, Luo X.Physiological effects of chitosan coating on wheat growth and activities of protective enzyme with drought tolerance.Journal of Soil Science. 2012;2:282-288.doi.org/10.4236/ojss.2012.23034.

[3] Lopez-Moya F, Escudero N, Zavala-Gonzalez EA et al Induction of auxin biosynthesis and WOX5 repression mediate changes in root development in Arabidopsis exposed 
to chitosan. Scientific Report. 2017;7. 16874-16875 doi.org/10.1038/s41598-017-168745.

[4] Guan YJ, Hu J, Wang XJ, Shao CX Effects of seed priming with chitosan solutions of different acidity on seed germination and physiological characteristics of maize seedling. Journal of Zhejiang University (Agriculture and Life Science). 2005;31(6):705-708.

[5] Batool M, Asghar, R. (2013) Seed priming with chitosanimproves the germination and growth performance of ajowan (Carumcopticum) under salt stress.Eurasia Journal of Bioscience. 2013;7:69-76. oi.org/10.5053.

[6] Manjunatha G, Roopa KS.Chitosan enhances disease resistance in pearl millet against downy mildew caused by Sclerosporagraminicola and defencerelated enzyme activation. Pest Management Sciences. 2008;64:12501257.doi.org/10.1002/ps.1626.

[7] Mourya VK, Inamdar NN. Chitosan-modifications and applications: Opportunities galore. Reactive \& Functional Polymers. 2008;68:1013-1051.

[8] Varlamov VP, Il'ina AV, Shagdarova BT, Lunkov AP, Mysyakina IS. Chitin/Chitosan and Its Derivatives: Fundamental Problems and Practical Approaches. Biochemistry (Mosc). 2020. 85(1): 154-176. doi: 10.1134/S0006297920140084. P

[9] Badawy MEI, Rabea El. Potential of the biopolymer chitosan with different molecular weights to control postharvest gray mold of tomato fruit.Postharvest Biology and Technology. 2009;51:110-117.

[10] Shagdarova, Balzhima \& Ilyina, A. \& Lopatin, S. et al. Study of the protective activity of chitosan hydrolysate against septoria leaf blotch of wheat and brown spot of tobacco.Applied Biochemistry and Microbiology. 2018;54(1):71-75. 